11 ( $12 \times 11$ 112

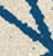
$1 \times 11$ 1..

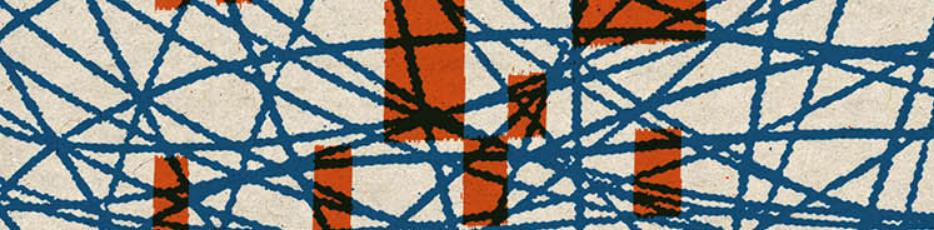

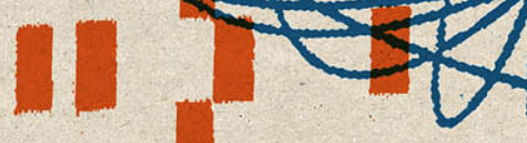

$+$
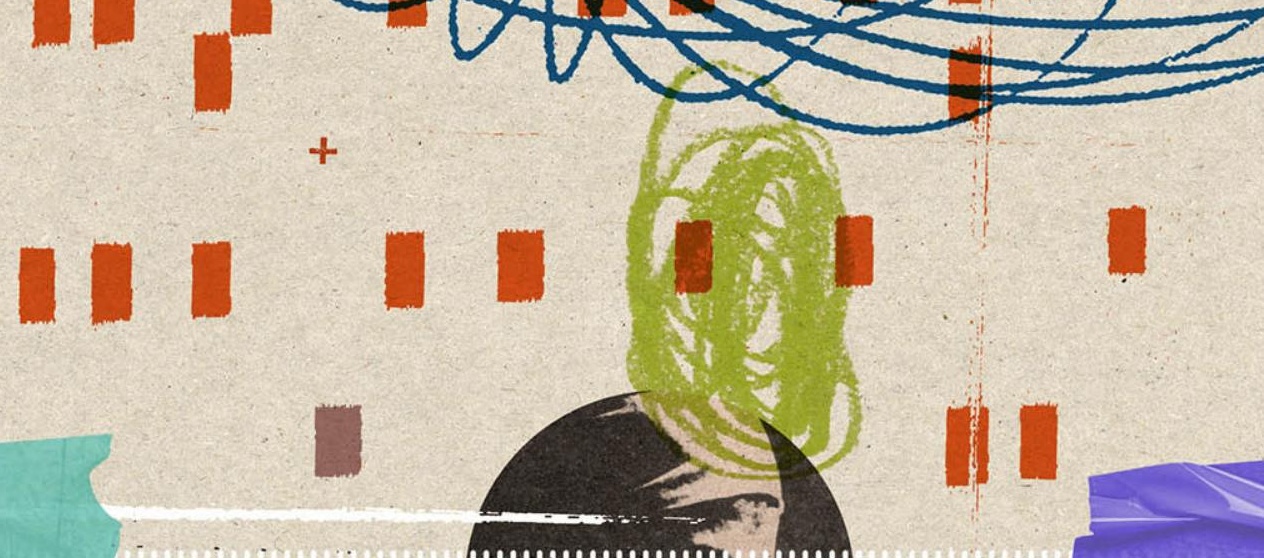

$$
14+
$$

II) 41 - 


\title{
Pobreza e desenvolvimento: imaginários coloniais e insurgências teóricas desde o Sul
}

\section{Poverty and development: colonial imaginary and theoretical insurgencies from the South}

\author{
Pâmela Marconatto Marques* | Dayana Cristina Mezzonato Machado** \\ http://dx.doi.org/10.51861/ded.dmvu.1.003 \\ Recebido em 15 de janeiro de 2021. Aceito em 25 de fevereiro de 2021.
}

\begin{abstract}
Resumo
No presente ensaio, pretendemos situar coloniais imaginários correntes sobre pobreza, sondando suas implicações nas políticas de desenvolvimento rural. A partir de uma contribuição teórica insurgente, acionada por intelectuais do Sul do mundo, como os haitianos George Anglade e Jean Casimir, o iraniano Majid Rahnema e o beninense Albert Tevoedjrè, temos como propósito desestabilizar o emprego unívoco do termo, adicionando tensão a esse campo de estudos. Nesse esforço, esboçamos a gênese da chamada pobreza global, localizando seus mecanismos de exotização via demonização e docilização dos corpos decifrados como pobres - aproximando-nos, nesse sentido, da caixa de ferramentas arqueológicas colocada à disposição por Michel Foucault. Na sequência, enveredamos por imaginários hegemônicos da pobreza verificados no Brasil, capazes de forjar desde personagens como Jeca Tatu até políticas públicas desenvolvimentistas. Finalizamos o ensaio afirmando, em aliança com os teóricos selecionados, a importância de pensarmos a pobreza como fenômeno multifacetado, complexo e histórico, definido sempre em suas relações. Conclui-se apontando para a necessidade epistemológica de desamalgamar pobreza e miséria ao realizarmos nossas pesquisas, de associar miséria à riqueza extrema e, finalmente, de interpelar a pobreza como portadora de saberes sobre a manutenção da vida e do laço social.
\end{abstract}

Palavras-chave: Miséria, Pobreza, Desenvolvimento, epistemologias do Sul.

\begin{abstract}
In this essay, we intend to situate current colonial imaginary about poverty, probing its implications for rural development policies. Based on an insurgent theoretical contribution, triggered by intellectuals from the South of the world such as Haitians George Anglade and Jean Casimir, Iranian Majid Rahnema and Beninese Albert Tevodjrè, we aim to destabilize the univocal use of the term, adding tension to this field of studies. In this effort, we outlined the genesis of the so-called global poverty, historicizing it and locating its exoticization mechanisms via demonization and docilization of bodies deciphered as poor, approaching, in this sense, the archeological toolbox made available by Michel Foucault. In the sequence, we embarked on hegemonic imagery of poverty verified in Brazil, capable of forging from characters like Jeca Tatu to developmental public policies. We ended the essay by affirming, in alliance with the selected theorists, the importance of thinking of poverty as a multifaceted, complex and historical phenomenon, always defined in their relationships. It concludes by pointing to the epistemological need to de-amalgamate poverty and misery when carrying out our research, to associate misery with extreme wealth and, finally, to interpellate poverty as a carrier of knowledge about the maintenance of life and the social bond.
\end{abstract}

Keywords: Misery, Poverty, Development, Epistemologies from the South

\footnotetext{
* Professora do Programa de Pós-Graduação em Desenvolvimento Rural da UFRGS. https://orcid.org/0000-0003-0630-9546.E-mail: pmarconatto@gmail.com

** Doutoranda do Programa de Pós-Graduação em Desenvolvimento Rural da UFRGS. https://orcid.org/0000-0002-7212-0525.E-maill: dayanacmma@gmail.com
} 


\section{INTRODUÇÃO}

$\mathrm{O}$ argumento a ser apresentado nesse texto é fruto do encontro das autoras com teorias sociais produzidas em espaços comumente associados apenas à miséria, privação e tragédia. Ele se ampara sobre a noção de que aquilo que se convencionou chamar de pobreza não é um fato inerte da natureza, não está meramente ali, mas trata-se de uma ideia que porta uma narrativa, um imaginário, uma estética e um vocabulário que lhe dão realidade em e para determinado grupo e contexto histórico-político. Trata-se, portanto, de uma contribuição teórica cujo propósito é sondar imaginários e desestabilizar o emprego unívoco do termo, adicionando tensão a esse campo de estudos.

Se considerarmos que entre os aymaras bolivianos pobre é "aquele que não tem familia”, ou que entre algumas comunidades indígenas amazônicas, pobre equivale a "solteiro" já conseguiremos perceber que a pobreza é, nesses contextos, medida pela amplitude das relaçôes, definida como condição daquele que está sozinho para dar conta de sua vida. Já entre os hindus, pobreza implica uma subsistência baseada na simplicidade, frugalidade, suficiência e respeito por tudo que é vivo. Esses exemplos singelos nos ajudam a sondar a pluralidade de entendimentos vigentes sobre pobreza, e sublinhar a necessidade de pensarmos nela como fenômeno multifacetado, complexo, definido sempre em suas relaçóes, sempre histórico e sempre situado.

Tal modulação se torna imperativa à medida que somos confrontados com um determinado entendimento de pobreza que se tornou hegemônico e, que, apesar de ser filho de um dado arranjo político, celebrado em um contexto histórico bem preciso, apresenta-se como universal e unívoco e segue lastreando desde a produção de conhecimento sobre pobreza como campo científico até o desenvolvimento de políticas públicas e projetos de intervenção multilateral.

Atentas a esses desdobramentos, trataremos, nesse ensaio, de testar outras lentes para o enfrentamento da discussão sobre pobreza. Para tanto, mobilizaremos teorias produzidas desde espaços historicamente marginalizados, situados no Sul do mundo - este entendido mais enquanto lugar epistêmico do que geográfico - e que apesar de se mostrarem potentes, como pretendemos apresentar, ficaram nas sombras, ativamente construídas como inexistentes pelo conhecimento acadêmico-científico dominante. Três teóricos terão proeminência nesse esforço: o iraniano Majid Rahnema, o beninense Albert Tévoédjrè e o haitiano Georges Anglade.

Majid Rahnema nasceu em 1924, no Teerã, capital iraniana. Aos trinta anos, Rahnema passou a representar seu país nas Naçôes Unidas, atribuição que exerceu por treze anos consecutivos. Durante seu trabalho na ONU, atuou como comissionado em Ruanda e Burundi, onde contribuiu 
nos processos de independência desses países, sendo ainda residente comissionado no Mali. Entre 1967 e 1971, foi Ministro da Ciência e do Ensino Superior do Irã, abdicando do cargo para fundar, junto com camponeses da província de Luristan, o Centro de Estudos de Desenvolvimento Endógeno (CEDE) (SICILIA, 2015). Sua vasta experiência em países considerados "subdesenvolvidos" contribuiu para a elaboração de uma contundente crítica ao desenvolvimento ocidental moderno e sua sistemática produção de miséria. Por meio do CEDE buscava aplicar suas preocupaçôes sobre a pobreza ao trabalho prático, criando, junto a uma equipe multidisciplinar, o Projeto de Desenvolvimento Integrado Selseleh (SIDP), que tinha como objetivo apoiar o povo nômade Luri no enfrentamento das grandes dificuldades emergentes da sedentarização forçada que viveram, sob as políticas do Xá. Professor universitário no Irã, Estados Unidos e França, foi um teórico importante na temática do desenvolvimento e da pobreza, produzindo obras como Global poverty: a pauperizing myth (1991); Le Nord perdu, repères pour l'après développement' (1992); The Post-Development Reader (1997), Quand la misèrechasse la pauvreté (2003) e La puissance des pauvres, Actes Sud (2008) (SICILIA, 2015; DEVELOPMENT WORKSHOP, 2021).

Nascido em 1929, em Porto Novo, Benin e conhecido como o "Artesão da democracia do Benin”, Albert Tévoédrjè foi um importante político e escritor, defensor de uma África econômica e politicamente livre. Sua atividade política iniciou no movimento estudantil, em Toulouse, França, onde fazia seus estudos na década de 1950, quando chegou a ser um dos líderes da Federação de Estudantes Negros na França e editor do jornal L’Étudiant Noir, fundado por Aimé Césaire e outros teóricos da Negritude. Tévoédrjè dedicou-se a combater as pressóes coloniais em África, e na luta pela independência ajudou a fundar o Movimento de Libertação Nacional Africano. Teve grande atividade política em seu país, em especial na luta anticolonial e pela democracia, atuando como Secretário de Estado de Comunicação em 1960, logo da independência do Benin. Teve importante carreira internacional, sendo nomeado secretário-geral da União Africana e Malgaxe em 1961 e diretor geral do Instituto Internacional de Estudos Sociais na África em 1974, junto ao escritório da Organização Internacional do Trabalho (OIT). Depois de um golpe militar, em 1964, Tévoédrjè, foi convidado para atuar no Centro de Assuntos Internacionais da Universidade de Harvard. $\mathrm{Na}$ década de 1990, foi ainda deputado e ministro. Como professor universitário de economia dedicou-se a temas centrais da relação norte-sul publicando L’Afrique revoltée (1958) e Pobreza, a riqueza dos povos (1978), dentre outros (VIDJINGNINOU; MILLECAMPS, 2019). 
Georges Anglade nasceu em 1944 na cidade de Porto Príncipe, capital do Haiti. Ainda no país natal estudou direito e ciências sociais, e aos 21 anos iniciou doutorado em geografia, na França. Lá, cursou Letras na universidade de Estrasburgo, e a escrita passaria a fazer parte de sua vida (UQAM, 2010). Com a ditadura Duvalier, exilou-se no Canadá em 1969, onde envolveu-se na criação do curso de Geografia na Universidade do Quebec em Montreal (UQAM). Anglade trilhou o caminho de uma geografia social aplicada, assumindo riscos na luta pela democracia haitiana, combatendo as ditaduras de papa Doc e baby Doc, sendo, por essa razão, preso duas vezes. Além de grande defensor da cultura haitiana e caribenha, presente em seus romances, contribuiu com a resistência à ditadura em Montreal fundando o Movimento de Solidariedade Haitiana, foi um grande lutador, lúcido e rigoroso. Atuou também no cenário político, sendo ministro do Transporte e das Comunicações no governo de Jean Bertrand Aristides, quando a democracia retornou ao país. Em 2002, aposentou-se como professor da UQAM e retornou ao Haiti. Autor de várias obras como L'espacehaïtien (1974), La géographie et son enseignement (1977), Mon pays d'Haïti (1977), La présence étrangère en Haïti (1980), Atlas critique d'Haïti (1982), Eloge de la pauvreté(1983), Cartes surtable (1990), LesBlancs de Mémoire (1999), Leursjuponsdépassent (2000), Cepaysqui m'babite (2002), L'espace d'une génération (2004), Chronique d'une esperance (2008). Em 2010, ele e sua esposa, a antropóloga Mireille Anglade, morreram durante o forte terremoto que atingiu Porto Príncipe (BEUVE-MERY, 2010).

Apostamos que as questóes levantadas por esses autores, algumas delas atualizadas por nossas inquietações, poderão contribuir com os desafios inscritos no tempo que nos coube viver, quando o fosso entre os miseráveis e os extremamente ricos, além de naturalizado, está se tornando cada vez mais profundo. Para tanto, organizamos esse ensaio em quatro seções. A primeira delas tem como objetivo situar brevemente a noção de "pobreza global" em sua gênese histórico-política; a segunda propóe-se a apresentar enfrentamentos insurgentes desde o Sul, marcados pela desestabilização do marco apresentado na seção anterior; a terceira localiza a tensão no imaginário brasileiro e a quarta e última propóe-se a apresentar, já encaminhando o final do argumento, a estratégia de desamalgamar pobreza e miséria como movimento epistêmico insurgente.

\section{A NOÇÃO DE POBREZA GLOBAL E SUA GÊNESE}

A noção de pobreza global pode ser localizada no contexto pós-segunda guerra mundial, com a criação da Organização das Naçôes Unidas e a cele- 
bração de um novo consenso - de que a única possibilidade de evitar-se a guerra estava em uma paz conquistada pela via do desenvolvimento. Essa afirmação, nesse momento histórico, foi bem recebida nos países do sul do mundo, muitos dos quais, no continente africano e asiático, se encontravam mobilizados ou acabavam de sair vitoriosos de lutas revolucionárias por independência contra colonizadores que integravam a cúpula da organização recém-criada.

Havia esperança, assim, de que a proposta pudesse se tratar de um acerto de contas, de finalmente ter-se a possibilidade de um ajuste advindo do reconhecimento das feridas atrozes impostas pelo colonialismo, entre elas o processo de destituição das populaçóes tradicionais, espoliação das riquezas de seus territórios e construção ativa de seu empobrecimento pelos colonizadores. Essa esperança também se alimentava do fato de que a guerra a que se punha fim havia sido coordenada contra um regime fundado sobre o racismo, e intelectuais europeus, como Hannah Arendt (1989), levantavamse para dizer que o humanismo ocidental era oco. Que a ideia de civilização sobre a qual o Ocidente se havia construído e legitimado não havia dado conta de impedir os horrores do holocausto. Ou seja: estava no ar a impressão de que os dias de gloria e regozijo dos antigos colonizadores haviam chegado a seu ocaso e que, como bem recomendou o pensador martinicano Aimé Cesaire (1978) havia chegado o momento de descobrir que uma civilização fundada sobre a violência, sobre a escravidão, sobre sangue e morte de populaçôes inteiras trazia, em seu âmago, um Hitler que, se havia sido ignorado até aquele momento como possibilidade, era por pura falta de lógica.

Nada poderia estar mais distante do que se seguiu. Nesse contexto, a noção de desenvolvimento passa a operar como eixo irradiador de uma nova organização global, ao mesmo tempo em que, conforme sugere o filósofo argentino Walter Mignolo (2008, p. 293) torna-se um termo para esconder a reorganização da lógica colonial na vigência do que era afirmado como nova modernidade, admitindo "novas formas de controle e exploração do setor do mundo rotulado a partir de então como Terceiro Mundo e países subdesenvolvidos".

Amalgamada a essa noção de desenvolvimento e a seu uso estratégico no período mencionado, Majid Rahnema (2010) afirma que emergirá a noção de pobreza global.

A pobreza global é uma construção inteiramente nova e moderna. Os materiais básicos envolvidos em sua construção são essencialmente a monetarização da vida e a integração forçada das sociedades vernaculares na economia mundial. Em um de seus primeiros relatórios, o Banco Mundial correlaciona de perto o problema da pobreza global com os produtos nacionais brutos dos países. Postu- 
la que os países com uma dada renda média per capta são, por definição, pobres e subdesenvolvidos. Expressa a responsabilidade das naçóes mais ricas, sendo a mais rica os Estados Unidos, de ajudar os países pobres a elevar seus padróes de vida. Assim, pela primeira vez na história, naçóes e países inteiros passaram a ser considerados (e se considerarem) pobres, sob o argumento de que sua renda total é insignificante em comparação com aqueles que hoje dominam a economia mundial. Consequentemente, a renda nacional foi introduzida como uma nova medida global para expressar os vários estágios do desenvolvimento econômico, proposto como a resposta final à pobreza. (RAHNEMA, 2010, p. 178)

Esse foi o mote por meio do qual os mais de quarenta países africanos e asiáticos recém-independentes fossem rapidamente decodificados, ao ingressarem na Organização das Nações Unidas, como pobres ou "subdesenvolvidos”. Meio eficaz de converter a potência revolucionária acionada nos processos de libertação em carência estrutural a ser revertida graças às naçóes do Norte, vinculadas a esse cenário não por meio de políticas de reparação, mas por meio de um novo chamado moral, missionário. A suspeita que gostaríamos de instalar é a de que essa pobreza denunciada pela nova estrutura de manutenção da paz foi desligada, através do discurso, dos processos de espoliação colonial e imputada apenas às suas vítimas. Como consequência da suposta ignorância, de tradições arcaicas, do obscurantismo, da feitiçaria, do atraso, da indolência, da preguiça dessas populaçôes. Desse modo, os espaços decodificados como "terceiro mundo" passam a compor o imaginário desenvolvimentista como não contemporâneos das naçôes ditas modernas, como passado a ser superado. É importante frisar que aí opera mecanismo semelhante àquele acionado para desvincular o que se reconhecia como subdesenvolvimento ou pobreza em África, Ásia e América Latina do estado de desenvolvimento vivenciado pelas potências europeias, como se se tratassem de processos absolutamente desvinculados. Compreender essa dissociação como manobra é importante porque ela acaba lastreando o modo como nos relacionamos com a pobreza dentro de nossos países - como se os processos de empobrecimento de uma dada parcela da população não estivesse profundamente vinculados ao enriquecimento ilegítimo, espúrio, de outra. Albert Tévoédjrè (1978, p. 151) chega a dizer que em países marcados pela desigualdade social, "quem possui o supérfluo, possui bens de outrem".

A noção de pobreza global emergente desse contexto de reconfiguração hegemônica conta com mecanismos discursivos que lhe dão sustentação. O primeiro deles é a enunciação da pobreza como lugar vazio de desenvolvimento, marcado apenas pelo que lhe falta, todo carência, debilidade, enfermidade, prostração. Entrará em curso, aí, um processo de exotização da pobreza por duas vias: I) a demonização do pobre que se manifesta através do discurso de ódio que o repudia como abjeto, estranho, perigoso, que deve ser 
impedido, contido, limitado, punido no seu afã de proliferar filhos, doenças, feitiços, crimes; e II) a construção da pobreza como corpo dócil, necessitado de tudo, grato por tudo e passivamente entregue à ajuda e à caridade alheias. Podemos verificar essas duas tendências em duas narrativas muito interessantes. A primeira delas é o conto "os pobrezinhos" do escritor português António Lobo Antunes, que vai se tornar escritor por acaso, quando, sendo enviado como médico para atuar na guerra colonial pela independência da Angola, vê-se impelido a elaborar o que vê e denunciar o colonialismo português.

Na minha família os animais domésticos não eram cães nem gatos nem pássaros; na minha família os animais domésticos eram pobres. Cada uma das minhas tias tinha o seu pobre, pessoal e intransmissível, que vinha a casa dos meus avós uma vez por semana buscar, com um sorriso agradecido, a ração de roupa e comida. Os pobres, para além de serem obviamente pobres (de preferência descalços, para poderem ser calçados pelos donos; de preferência rotos, para poderem vestir camisas velhas que se salvavam, desse modo, de um destino natural de esfregóes; de preferência doentes a fim de receberem uma embalagem de aspirina), deviam possuir outras características imprescindíveis: irem à missa, batizarem os filhos, não andarem bêbedos, e sobretudo, manterem-se orgulhosamente fiéis a quem pertenciam. (ANTUNES, 1996, p. 80).

Por meio de uma ironia perturbadora, Antunes evidencia o comportamento do homem moderno (nesse caso, representado pelas tias "ricas") ao descrever o que esses buscam encontrar nos "pobres”, ou seja, um bom "pobre” deve ser sempre educado, grato, contido e crente. Numa definição clara de papéis, na sociedade moderna os "pobres” são produzidos como corpos dóceis, moralizados, devendo, com sua existência, disponibilizar-se a cumprir com os anseios das "generosas" classes abastadas, brancas, coloniais.

A segunda se trata do discurso que marca a chegada de Henri Truman à presidência dos EUA, em 1964. Ele diz:

Mais da metade da população do mundo vive em condiçóes abjetas. Sua alimentação é inadequada, é vítima de enfermidades. Sua vida econômica é primitiva e está entancada. Sua pobreza constitui um obstáculo e uma ameaça tanto para eles como para as áreas mais prósperas. Pela primeira vez na historia, a humanidade possui conhecimento e capacidade para aliviar o sofrimento dessa gente. Creio que deveríamos colocar à disposição dos amantes da paz os benefícios de nosso acervo de conhecimento técnico para ajuda-los a conquistar uma vida melhor. O que temos em mente é um programa de desenvolvimento. Produzir mais é a chave para a paz e a prosperidade. E a chave para produzir mais é uma aplicação melhor e mais vigorosa do conhecimento técnico e científico moderno. (TRUMAN, 1964 apud ESCOBAR, 2007) 
O discurso de Truman marca o início da corrida pelo desenvolvimento apresentado como projeto mundial, encabeçado pelos Estados Unidos e dirigido contra uma pobreza afirmada a um só tempo como débil e perigosa, dita global, mas estrategicamente localizada no Sul do mundo. Esse projeto contará com uma rápida institucionalização e vasta capilarização, verificada na proliferação de agências, centros de pesquisa, departamentos de estado, organizações não governamentais, institutos, fundos de apoio, parcerias, todos produzindo e demandando especialistas, todos produzindo e demandando estrutura física robusta e dispendiosa e carreiras de alto escalão - a pobreza localizada no Sul, promovendo a circulação de muito, muito dinheiro no Norte.

Exemplo disso é a criação da USAID (Agência Estadunidense para o Desenvolvimento Internacional), em 1949, como programa no marco da política externa norte-americana, elevada à agência estatal por Truman e orientada, como nos informa de maneira surpreendentemente objetiva seu site oficial na seção "Quem somos nós”, "História”, a dois objetivos centrais: I) Criar mercados para os Estados Unidos por meio da redução da pobreza e aumento da produção nos países em desenvolvimento; II) Reduzir a ameaça comunista ajudando os países a desenvolverem-se sob o regime capitalista.

$\mathrm{Na}$ sequência desse relato histórico, somos informadas de que, uma vez criada a USAID, "as oportunidades de trabalho em assistência ao desenvolvimento internacional cresceram tremendamente". Como não confiam nos governos terceiromundistas, financiar ONGs sediadas no Norte passa a ser o modo como se declara Guerra à pobreza no Sul do mundo.

No imaginário fomentado por organismos nacionais e internacionais de auxílio ao desenvolvimento, a superação da desigualdade social só admite como polo problemático a pobreza. É ela que deve ser submetida à guerra, à transformação, a políticas de superação, enquanto a riqueza segue podendo desdobrar-se de modo desmedido (no sentido de que se carece de meios de mensurá-la), protegida e imune a investidas em prol da redução da desigualdade. Enquanto a pobreza como objeto da teoria social, da pesquisa social, parece entregar-se transparente a especialistas, que na maioria das vezes sem qualquer pudor ou empecilho ético, enveredam sem pedir licença em espaços de intimidade, como se a pobreza portasse algo de público e aberto, numa efetiva docilização daqueles corpos, a riqueza extrema segue indisponível ao pesquisador, que, por sua vez, não conta sequer de metodologias que deem conta da especificidade da situação dos "podres de ricos" (CATTANI, 2019), os "global winners".

A doutrina Truman, como ficou conhecida, propunha uma revolução dos países “atrasados” os quais deveriam ser urbanizados, industrializados, 
ter crescimento produtivo e adotarem níveis de vida, educação e valores culturais modernos. Em 1951, as Nações Unidas chegam a divulgar um documento no qual afirmam que o progresso econômico implicaria em ajustes doloridos, e, portanto, filosofias ancestrais deveriam ser deixadas para trás de modo que essas "sociedades subdesenvolvidas" passassem por uma reestruturação. Desse modo, após a II Guerra, o discurso canônico passou a apresentar o mundo dividido entre os países desenvolvidos e os subdesenvolvidos. A noção de desenvolvimento passou a ser central para os programas e estratégias dos organismos internacionais e governos, e a pobreza apresentada enquanto um fenômeno terceiromundista a ser combatido, evidenciando a ausência de desenvolvimento ${ }^{1}$.

Enquanto as noções de crescimento e desenvolvimento econômico vão sendo construídas como discurso que as dissocia completamente do que se afirma como pobreza, vai se concretizando uma noção de que é por meio do crescimento econômico que se chegará ao desenvolvimento, o único modo de combater a pobreza. A consequência prática desse discurso são os projetos e programas de intervenção em países categorizados como de Terceiro Mundo.

\section{OS RISCOS DA GENERALIZAÇÃO: LEVANTES EPISTÊMICOS DESDE O SUL}

$\mathrm{Na}$ mesma linha reflexiva que apresentamos até aqui, o sociólogo venezuelano Edgardo Lander (2000) também considera que a pobreza na Ásia, África e América Latina foi "descoberta" no período do pós II guerra mundial, e para ele esse mecanismo se deu a partir de uma definição estritamente econômica e quantitativa. De modo arbitrário, em 1948 o Banco Mundial definiu como pobres aqueles países cujos ingressos anuais eram inferiores a US $\$ 100$ per capta. Foi assim que dois terços da humanidade acabaram transformados em pobres, e consequentemente, carentes de intervenção. A solução para tamanho problema seria o desenvolvimento. Assim, poderíamos assumir que a noção de desenvolvimento tem sua gênese no Ocidente a partir da criação de anormalidades (os "pobres”, os "desnutridos”, os “analfabetos”, as "mulheres grávidas", os "sem terra”), as quais deveriam ser reformadas (LANDER, 2000).

A pobreza é criada, então, enquanto fenômeno que manifesta estritamente o atraso e o subdesenvolvimento, sendo necessário, (o que soa quase como óbvio!), combatê-la. Interessante notar que essa noção de pobreza, construída exclusivamente como "falta", atraso, carência, foi problematizada em 2001 por Majid Rahnema em seu artigo The Riches of the Poor 
(As riquezas dos pobres). Nele, o diplomata iraniano afirma que a pobreza tem sido vista apenas como estado de destituição, de carências materiais e de miséria degradante. Para ele, reduzi-la a esse somatório de "faltas" é um erro que tem impedido a realização de um debate sério sobre a pobreza:

O que hoje é chamado de pobreza é um conceito socialmente fabricado que tende a despojar o povo, colocado sob um conceito arbitrariamente definido "linha de pobreza", de desenvolver suas próprias riquezas, as riquezas que lhes permitiram durante toda a sua história não cair na indigência. (RAHNEMA, 2001, p. 3).

Ao fazer uma arqueologia da pobreza, o autor identificou que historicamente a pobreza significou coisas muito diferentes para diferentes grupos. Acreditar que a pobreza é uma questão de carências a serem superadas por meio da integração de todos em um sistema de produção tecnologizado, cujo objetivo é a transformação das pessoas "pobres” em "ricas”, é uma premissa falsa e perigosa na visão do autor. Primeiro, porque não é possível definir a "falta em si”, já que cada grupo social tem percepçôes próprias sobre carências, e, segundo, porque as propostas de integração modernizadora têm criado novas carências, ainda mais difíceis de serem superadas. Desse modo, Majid afirma que a pobreza (assim como a riqueza) é muito mais complexa e específica em cada cultura, do que sua redução à "falta".

Pâmela Marques (2017), em sua tese de doutorado, afirma que a estratégia de construção desse discurso, que atribui ao Outro a condição de atrasado (na melhor das hipóteses em situação de transição) trata-se de técnica que quando aplicadas à pobreza passa a "decodifica-la como lugar abjeto, impotente, vazio de criatividade, que, no máximo, deve inspirar a solidariedade dos Estados "desenvolvidos" (MARQUES, 2017, p. 72)":

A caracterização de expressões culturais das comunidades que vivem nesses espaços associados à pobreza como "tradicionais" ou "não modernas", situando-as em processo de transição rumo à modernidade funciona como artifício discursivo para inseri-las como passado/margem no espaço/tempo moderno/colonial, e, assim, negar-lhes a possibilidade de serem compreendidas como dinâmicas culturais ou cosmovisões empenhadas na conquista de bem viver aqui e agora, fora da lógica ocidental/capitalista. (idem)

O sociólogo haitiano Jean Casemir (1980), em seu clássico “culturas oprimidas" destaca a matriz racial de poder que vai marcando o lugar de corpos não brancos nesse panorama mundial marcado pela persistência da colonialidade, onde ser subdesenvolvido é como ser um indígena latino-americano ou um negro africano. Verbalizar isso nos ajuda a entender o processo que Casemir chama de envilecimento, a que teriam sido submetidas as práticas e 
saberes com que essas populações criaram possibilidades de manter a vida e o laço social, e denunciadas como arcaísmo, ignorância, obstáculo ao desenvolvimento, mal que deve ser extirpado.

No limite, a pobreza a que se decreta guerra acompanha os corpos-saberes negros onde eles se aglomeram, a ponto de Majid Rahnema perguntar-se, em plena reunião de cúpula das naçóes unidas, se o plano é "erradicar a pobreza ou os pobres”. Rahnema (2001) vai dizer que a vida dos pobres quase sempre foi marcada por discriminações sociais, injustiças e humilhaçóes de todos os tipos. "As atitudes dos "não pobres” em relação a eles têm sido tão egocêntricas e desdenhosas que a pobreza, como um todo, tem sido assimilada apenas como estado de destituição, de carências materiais e de miséria degradante" (RAHNEMA, 2001, p. 2).

Envilecer a pobreza: partir do pressuposto de que toda a pobreza é igual e decretá-la sempre vil é um modo de colonizar a vida pelo discurso. De impedir que a pobreza seja vista em sua heterogeneidade e mais, que uma certa pobreza deixe de ser apontada e estigmatizada como problema social na mesma medida em que uma certa riqueza possa ser identificada como tal. Trata-se de uma nuance delicada e perigosa e reafirmamos, nesse ponto, a necessidade de manter a tensão que o tema exige, de modo que não seja capturado pelo discurso simplista de que não há pobreza ou que ela não deve ser objeto de qualquer política pública.

No Haiti, a teoria social também convida a esse movimento: George Anglade, em discurso chamado "elogio à pobreza" proferido pela ocasião de recebimento de um prêmio na Universidade do Quebec pelo conjunto de sua obra vai começar dizendo:

(...) não considero dignos de elogio nem as naçốes empanturradas de lucros e tampouco a pujança armamentista, e ainda menos esse ouropel de honrarias concedidas a serviço do poder. Estando já adiantado em minha jornada, eu nada encontrei mais digno de elogio do que a pobreza; não a miséria repugnante e abjeta, inaceitável em sua negação da dignidade humana, mas a pobreza, aquela que com obstinação feroz se tem desejado transformar sem jamais questionar que saberes porta acerca da sobrevivência, de que práticas dispõe, dignas de serem novos pontos de partida. Soube-se descrevê-la sem compreendê-la, lamentala sem respeitá-la, e sobretudo, soube-se amalgamá-la à miséria para desativar a alternativa de que está plena. Se a miséria persiste e ainda se cola a nós, é que não escolhemos partir da pobreza, mas de métodos de trabalho e de modos de pensar que sacralizam a riqueza. (ANGLADE, 1983, p. 1)

Anglade (1983) enfatiza que a riqueza, enquanto mito fundador da modernidade, foi fixada como horizonte e paradigma universal de desenvolvimento para todos os povos e países, porém não é essa a realidade que se tem 
constatado. Esse modelo de desenvolvimento tem aprofundado as desigualdades e criado cada vez mais miséria.

A opulência e a riqueza enquanto sinônimos de desenvolvimento também foram problematizadas por Albert Tévoédjrè (1979) em seu livro "A pobreza, riqueza dos povos". Tratando de afirmar a acumulação selvagem como tóxica para o corpo social e responsabilizando-a por uma crescente miséria, o autor questiona por que o suposto "terceiro mundo", deveria agarrar-se "a um modelo já caduco e até por vezes objetivamente nefasto?” (TÉVOÉDJRÈ, 1979, p. 40). Assim como Anglade (1983) ele está questionando o discurso oficial da pobreza enquanto carência, afirmando que "a pobreza não é nem miséria, nem indigência. É a vida cotidiana conquistada com o trabalho” e, portanto, é preciso respeitá-la.

O que esses autores têm em comum parece ser a atenção ao fato de que, mesmo contra todas as investidas de despojo, a vida insiste em pulsar em territórios marcados pelo sofrimento colonial e porta saberes sobre a manutenção de mundos. Ainda, a atenção dos mesmos parece dar conta de associar a riqueza desmedida à miséria, evidenciando a segunda como produto histórico da primeira. Vemos, assim, a construção da miséria como processo, investida colonial, o que permite desfazer os estigmas brutais que imputam a características essencializadas de dados povos a condição de miséria em que vivem.

Esses textos importantes, capazes de enfrentar com coragem essa questão delicada, trazendo formulações desde espaços epistêmicos subalternizados seguem desconhecidos. As obras de Anglade e Rahnema, por exemplo, sequer têm tradução em português. Tévoédjrè, por sua vez, ainda que vertido para o português em plena ditadura militar e colocado em circulação por intermédio das pastorais da terra, vinculadas à teologia da libertação, também se manteve fora das discussões acadêmicas.

\section{O COMBATE À POBREZA NO BRASIL: ENTRE A DEMONIZAÇÃO E A CONSTRUÇÃO DE CORPOS DÓCEIS}

Chegam silenciosamente, ele e a 'sarcopta' fêmea, esta com um filhote no útero, outro ao peito, outro de sete anos à ourela da saia. (LOBATO, 2014, p. 165)

Nesse fragmento do conto "Velha Praga", Monteiro Lobato está descrevendo a chegada dos caboclos numa nova área de mata no interior paulista. Não é uma descrição qualquer, o autor nomeia o caboclo: "Sarcoptes", e "sarcopta fêmea" ao se referir às mulheres. "Este funesto parasita da terra éo 
CABOCLO, espécie de homem baldio, seminômade, inadaptável à civilização, mas que vive à beira dela na penumbra das zonas fronteiriças." (LOBATO, 2014, p. 165). Publicado em 1914 no jornal O Estado de São Paulo, o texto aponta a responsabilidade dos desastres ambientais, preocupação de Lobato, ao caboclo e a seu modo de vida. Segue: "À medida que o progresso vem chegando com a via férrea, o italiano ${ }^{2}$, o arado, a valorização da propriedade, vai ele refugindo em silencio, com o seu cachorro, o seu piläo, a pica-pau e o isqueiro" (idem). Muito mais que distinguir os possíveis culpados pelas queimadas, o autor está descrevendo e classificando um modo de vida específico, dando início à construção de um personagem clássico da literatura hegemônica brasileira, o Jeca Tatu.

Esse personagem ocupou espaço na política e na educação ao longo do século XX. Em 1918, Rui Barbosa utilizou o Jeca em sua campanha presidencial para simbolizar o atraso em que vivia o povo brasileiro (LOBATO, 2014). O personagem também foi alvo de campanhas sanitaristas que visavam educar as populações rurais, historicamente marginalizadas, para hábitos de higiene e medicação. O livro Urupês teve uma venda espantosa, chegando a sete ediçôes seguidas no início do século XX. Já em 1966, o almanaque "Jeca Tatuzinho" 3 chegou a ter a distribuição gratuita de 35 milhóes de cópias, mais tarde, na década de 1980, chegou a 100 milhóes de cópias distribuídas somente nas escolas. Diferentes modos de viver de um vasto rural no interior do Brasil foram reduzidos e genericamente classificados como atrasados, doentes, preguiçosos, e, portanto, inferiores e inviáveis. Exemplo clássico da demonização da vida simples, Jeca Tatu sintetizava a visão das elites brasileiras sobre modos de existir no rural, estereotipados como miseráveis. É preciso entender, nesse ponto, que a emergência do personagem se dá no contexto de recente abolição, em que o componente africano do povo brasileiro passa a ser apontado como óbice a seu desenvolvimento e a mestiçagem desponta como projeto de redução étnica e missão civilizatória, bússola apontada para o branco europeu ${ }^{4}$.

Às populações rurais passa a ser imposto um modelo de vida unívoco, no qual o abandono das suas práticas, classificadas como atrasadas, e a adoção de tecnologias modernas seria o caminho para alcançar a riqueza. Em um trecho do manual Jeca Tatuzinho diz:

Jeca Tatu era um pobre caboclo que morava no mato, numa casinha de sapé. Vivia na maior pobreza, em companhia da mulher, muito magra e feia e de vários filhinhos pálidos e tristes. Jeca Tatu passava os dias de cócoras, pitando enormes cigarrôes de palha, sem ânimo de fazer coisa nenhuma.

A história segue dizendo que o Jeca se contentava em caçar, pescar e coletar, sua casa era muito simples, tendo somente o necessário. Todo ano 
plantava uma rocinha de milho, feijão e abóbora. Tinha uns porquinhos e algumas galinhas, nada mais. Passava boa parte do seu tempo descansando à sombra com seu cachorro. Para o escritor, essa vida era sinônimo de miséria, e atribuiu-se então o estado de doença ao personagem. Um médico deu o diagnóstico: Jeca-Tatu estava enfermo, amarelão era a causa do seu cansaço e desânimo. Após ser medicado, com produtos que patrocinavam o manual onde está escrita a história, Jeca teve sua vida transformada. Comprou novas fazendas, automóvel, vários tipos de maquinários e aprendeu inglês. "Ficou rico e estimado, como era natural” (LOBATO, 1966, p. 13). Salta aos olhos a demonização de um modo de vida edificada na obra de Lobato como sinônimo de doença, indolência e destituição, ao mesmo tempo em que articula sua inviabilidade apresenta como modelo alternativo uma vida moderna, de opulência e riqueza que, ao final, conclui-se ser também fonte de estima.

Esse personagem contribuiu enormemente para a construção do imaginário sobre a pobreza rural no Brasil. Jeca-tatu tornou-se muito popular e uma expressão ainda hoje usada, sendo encontrada nos dicionários brasileiros como "caboclo do interior brasileiro, morador da zona rural, de estilo de vida muito simples, caipira; jeca"s. Essa construção discursiva, que é parte de uma estratégia de desenvolvimento, teve efeitos muito concretos nas vidas das pessoas. A literatura consagrada de Lobato é um exemplo da narrativa que se construiu junto aos chamados países subdesenvolvidos, onde se reduziu a pobreza a um somatório de carências a serem superadas, em que a solução para essa lacuna estaria na integração de todos em um sistema tecnologizado, no qual pessoas "pobres" seriam transformadas em "ricas" (RAHNEMA, 2001). Tal narrativa foi extremamente perversa com os processos autóctones e autônomos das populaçôes de países colonizados, passou-se a combater a pobreza sem conhecê-la, sem reconhecê-la como resultado de despojo, e, principalmente, deixou-se de aprender com seus mecanismos e estratégias de construir vida digna em meio às dificuldades da herança colonial (ANGLADE, 1983).

A construção ácida de Lobato, caracterizando determinados modos de vida como sinônimo de atraso, preguiça e miséria, não está muito distante de outros estilos textuais que, apesar de mais palatáveis, estão carregados de sentidos muitos semelhantes. No documento "Relatório FAO/INCRA", de 1994, os autores afirmam que uma importante fatia da agricultura familiar tendia "à degradação, seja pela migração para as cidades, seja por meio da pulverização minifundiária que gera estabelecimentos de terceira categoria” (FAO/INCRA, 1994, p. 5). Tais estabelecimentos eram "subfamiliar e periférico", local de "residência e subsistência de uma mão-de-obra desempregada ou subempregada” (FAO/INCRA, 1994, p. 5)”. Esse relatório foi o 
resultado de um amplo diagnóstico realizado no espaço rural brasileiro no início da década de 1990 e se propunha estabelecer as bases para um novo desenvolvimento rural para o país. Apesar de ter sido amplamente utilizado como base para políticas públicas pioneiras dirigidas aos agricultores familiares, o documento esvaziou e tirou de cena milhóes de pessoas atribuindo a elas uma não-função, um não-lugar dentro de um "novo modelo de desenvolvimento rural”. Todas as vidas existentes nesses espaços foram transformadas em "terceira categoria", "subfamiliar", "periférico" e que, portanto, tendia "a degradação". Quase três décadas depois da edição do manual "Jeca tatuzinho" é impactante constatar que uma parte da população rural brasileira siga sendo destituída e demonizada, sendo vista como entrave, e no limite, perigo para o desenvolvimento nacional.

O Ministério do Desenvolvimento Social e Combate à Fome produziu uma série de materiais sobre o Plano Brasil Sem Miséria (PBSM) em que estão compilados artigos que apresentam o processo de construção, execução e resultados dessa importante política pública. Nesses materiais, percebemos uma mudança na narrativa, que abandona o discurso de demonização dos pobres rurais. O documento, ao contrário, está perpassado por valores que demonstram engajamento humanitário de seus autores. Ainda que haja esse giro, o entendimento de pobreza porta ainda um imaginário que a apresenta exclusivamente como "somatório de carências". Os beneficiários do programa são aqueles sem escolaridade, sem assistência técnica, sem terra, sem condições de lutarem pelos seus direitos, etc.Para a elaboração da política pública, os gestores apresentaram o seguinte diagnóstico dos "agricultores mais pobres":

As principais dificuldades dos agricultores mais pobres estão centradas, de um lado, na falta de apoio técnico para qualificar, aperfeiçoar ou mesmo iniciar as suas atividades produtivas e, por outro lado, na escassez de recursos para investir na melhoria da sua produção. [...] agricultores mais pobres, caracterizados, em sua maioria, pelo baixo aporte tecnológico, pela falta de insumos produtivos, pela pouca diversificação de sua produção e pelo baixo grau de associativismo e cooperativismo (MELLO et al, 2015, p. 17-18).

Em outro texto sobre o PBSM dizia: "os mais pobres, exatamente pelo nível de exclusão, abandono, desinformação e isolamento [...] são aqueles que tinham menos condiçóes de exigir seu direito a ter direitos" (CAMPELLO; MELLO, 2014, p. 35). O texto afirmava ainda que eram "carentes de condições de saneamento, acesso à água, energia e coleta de lixo, além de baixos níveis de alfabetização e ausência de documentos entre os membros das famílias" (CAMPELLO; MELLO, 2014, p. 40). Novamente, chama atenção o modo envilecido como essas populações são exclusivamente des- 
critas. Trata-se de um padrão a compor esses documentos, que, ao criarem a figura do miserável-beneficiário de políticas públicas, o obliteram como ser humano. Ainda que consideremos, em um primeiro momento, tratar-se de um documento de estado e não de um estudo acadêmico, onde as complexidades humanas teriam mais lugar e oportunidade para serem abordadas, devemos lembrar que normativas multilaterais, políticas públicas e pesquisa acadêmica vão gerando gramáticas específicas, repertórios hegemônicos que costumam reforçar-se, em um sistema circular e endógeno de auto-referenciação (MARQUES, 2017). Um dos resultados dessa lógica circular hegemônica é a dificuldade de penetração de novas gramáticas a partir das quais formular a luta social por direitos.

O que gostaríamos de evidenciar nessas breves passagens é o padrão exclusivamente focado naquilo que "falta" a essas populações. $\mathrm{Na}$ tentativa de justificar a importância e urgência de políticas públicas de desenvolvimento rural, as narrativas construídas pelos documentos tendem a reforçar imaginários de que tais populaçôes são "todo-carência”.

\section{DESAMALGAMAR POBREZA DA MISÉRIA COMO MOVIMENTO EPISTÊMICO DESCOLONIZADOR}

Talvez seja possível conceber que o Plano Brasil Sem Miséria, apesar de trazer a terminologia "Miséria", não conseguiu diferenciar pobreza de miséria, já que ambos os conceitos aparecem cruzados a todo momento, algumas vezes diferenciados por critérios exclusivamente monetários. Esses textos manifestam o amálgama que se construiu no discurso oficial entre pobreza e miséria, processo que se aproxima daquilo que Anglade já denunciava em 1983. Ambas foram fundidas de modo que se tornou quase impossível analisá-las separadamente e logo tratou-se de desejar transformar e combater a pobreza sem nem mesmo conhecê-la em profundidade. Como afirma Anglade (1983):

Com determinação, queríamos transformá-la sem nunca questionar que ela poderia estar ocultando um saber-fazer de sobrevivência, que poderia ter acumulado práticas dignas de ser o ponto de novos começos. Pudemos descrevê-la sem compreendê-la, apiedá-la sem respeitá-la e, sobretudo, amalgama-la com a miséria para melhor desarmar a alternativa de que ela está repleta. (ANGLADE, 1983, p. 14)

Da observação da realidade concreta haitiana e sua luta pela sobrevivência engajada por essas populaçóes contra a miséria, Anglade (1983) vê ali a potência de vidas sendo cotidianamente elaboradas, e sugere, portanto, um giro no modo de olhar e construir o discurso da pobreza. 
Do ponto de vista estritamente epistemológico, a construção de uma realidade de subdesenvolvimento sempre deu o olhar dos centros às suas periferias, dos dominantes aos seus dominados. Seria possível proceder de outro modo, chegar a uma leitura que fosse específica dos desfavorecidos sobre si e sobre os outros, uma espécie de dupla reversão nos discursos cujos pontos de ancoragem passariam dos centros às periferias, e na periferia dos ricos para os pobres? (Idem, p. 23)

Essa virada ética, política e epistemológica proposta pelo geógrafo haitiano encontra eco no trabalho do intelectual Albert Tévoédjre, que começa pela proposta de "desonrar o dinheiro", recusando a ostentação como modelo de desenvolvimento e, em seguida, para melhor compreender a pobreza, propóe ainda esse mesmo movimento metodológico de Anglade de libertá-la da associação com "algo que não a constitui: a indigência e a miséria”.

Ele propóe mais, que se amalgame a miséria à riqueza extrema: "é a acumulação desmedida de alguns que leva à existência de uma massa de indivíduos reduzidos à indigência e obrigados a recorrer à caridade pública ou privada para sobreviver. A miséria nasce da mesma civilização do esbanjamento". E vai decretar

“a acumulação acontece no organismo quando uma substância introduzida não
é nem absorvida devidamente e nem eliminada. Assim, ela se torna tóxica. Da
mesma forma, a riqueza quando significa acumulação desordenada torna-se tó-
xica para a sociedade onde está localizada porque a opulência não controlada
nem dominada produz adoecimento - o seu próprio e de seu ambiente”.

Ambos, Anglade e Tévoédjrè contrapõem-se à lógica desenvolvimentista que consiste na expansão a nível global do modelo americano de vida boa apresentando dois exemplos bem simples a partir da vida vivida em seus países e do encontro com funcionários de agências de desenvolvimento. Anglade cita o exemplo das casas leves no Haiti rural, que suportam as intensidades de furacóes e terremotos sem produzir escombros que matam. São tecnologias de manutenção da vida em contextos marcados por terremotos, tecnologias forjadas por corpos que precisam dar conta da vida sob ameaça constante. Tévoédjrè conta sobre quão problemática foi a adoção de telhas de zinco no Benin, parte da política modernizadora da década de 80 , financiada pelo Banco Mundial, que transformou as casas em verdadeiros fornos. As antigas tecnologias locais - tecnologias da vila - com as telhas de barro, são mais eficientes como isolantes térmicos e são menos dispendiosas. Ele cita ainda os fornos de barro que alimentavam vilas inteiras e não dependiam de combustível. Esses fornos tradicionais foram substituídos por fornos modernos que passaram, em sua percepção, a gerar escassez e não desenvolvimento. 
Sobre esse tema, a tese de doutorado do sociólogo haitiano Jean Anil Louis-Juste, defendida aqui no Brasil, traz uma crítica densa e aguda contra a “ajuda internacional” o que chama de solidariedade de espetáculo, em curso no Haiti:

a solidariedade desenvolvimentista (ou de espetáculo) conduz à total despolitização das relaçôes sociais que permitiram o empobrecimento de comunidades inteiras, esvaziando o conteúdo político do subdesenvolvimento através da conexão privada entre "pessoas generosas" e "pessoas carentes", mediatizada pela ONG. Essa subsunção contribui para ocultar as metas de antigas metrópoles na organização da vida e trabalho das populaçốes do Terceiro Mundo, além de manter moralmente a salvo a fortuna ilegítima de pouquíssimos. (JUSTE, 2014, p. 180-181)

Como Anglade, Tévoédjrè ressalta que só há miséria porque não se escolheu uma pobreza digna como parâmetro de desenvolvimento, colocandose em seu lugar uma riqueza opulenta, feita de consumo e desperdício, que sequer é conhecida pelas populaçóes, que nada disse ainda de contundente sobre as questôes candentes levantadas por Tevoedjrè.

Esse movimento simultâneo a que ambos nos convocam é importante para respeitar-se a pobreza como espaço de manutenção da vida e ao mesmo tempo desabilitar a ignição que faz dela o maior foco de atenção no combate à desigualdade social. Como efeito simultâneo, passa-se a ter percepção da riqueza extrema e desmedida como principal produtor, vetor e mantenedor de desigualdades. Desse modo, os autores nos provocam a pensar na tecnologia da vila, no reencontro do tempo de viver, na produção de respostas para bem viver e bem morrer que não partam da terceirização de tudo. Como acolher os familiares que envelhecem? Como fazer o amor durar? Como fazer do corpo uma usina de vitalidade e energia, pronto para o desafio de viver? Tratam-se, essas sim, questôes que devem nos importar no investimento criativo e existencial em bem viver, fora do léxico oferecido por projetos homogeneizantes de desenvolvimento.

Pensar o papel que as Ciências Sociais tiveram no projeto colonial atualizado pelas lógicas desenvolvimentistas do pós-segunda guerra implica pensarmos nossa atividade como exercício de violência epistêmica, entendida como colonização da vida pelo discurso. Verificamos, assim, o modo como nossa produção de conhecimento reforçou certas representaçóes de pobreza, contribuindo para que se tornassem dominantes, modulando com rigidez nossos modos de imaginar a realidade e interagir com ela, habilitando algumas associações - como, por exemplo, a relação entre riqueza e desenvolvimento - e interditando outras - como, por exemplo, a de pobreza e manutenção da vida ou a de riqueza desmedida e miséria. 


\begin{abstract}
"no momento atual, não se conhecem pesquisas de campo sobre as sociedades mineradoras, sobre as usinas açucareiras, sobre as companhias frutíferas, cafeeiras, etc. As ciências sociais esquadrinharam sabiamente o mapa do Caribe e da América Latina, sem, entretanto, perceber no seu caminho as visíveis instalaçóes imperialistas. Passando pente fino em cada canto do território latino-americano, o olhar da teoria social se limitou, no mais das vezes, a desvelar, de forma brilhante, as mitologias, os sistemas de parentesco, os preconceitos raciais, a literatura oral, os costumes sexuais e culinários, as criaçôes musicais e artísticas, a miséria das populaçóes, sem jamais se interessar, com o mesmo entusiasmo, pelas relaçôes históricas que existem entre o colonialismo e todo o manancial peculiar e contraditório de culturas e civilizaçôes. Onde estão os cientistas sociais para pesquisar os conselhos de administração dos Bancos e das Bolsas neocolonialistas? Onde está a antropologia das castas militares, das instituiçốes econômicas e políticas, dos mecanismos pseudo-jurídicos? Em resumo, quando serão esquadrinhadas as estruturas elementares do poder imperial que, em cumplicidade com as oligarquias indigenistas, continuam a subdesenvolver as sociedades americanas enquanto enriquecem de modo ilegítimo? (DEPESTRE, 1980, p. 7).
\end{abstract}

\title{
CONSIDERAÇÕES FINAIS
}

Ao final desse ensaio, cujo propósito foi o de sondar aproximaçôes, levantar fios que permitam futuras tramas, inspiradas por intelectuais do sul do mundo, experimentaremos sinalizar três esforços epistêmicos com potencial de descolonizar o modo de nos relacionarmos, desde as ciências sociais, com o que convencionamos chamar de pobreza.

O primeiro diz respeito à adoção, como procedimento teórico e metodológico, da distinção entre pobreza e miséria ao realizarmos nossas pesquisas sobre essa temática, como sugerem os três teóricos abordados. Para tanto, o marco monetário não é suficiente. Será necessário apostar em indicadores específicos. O segundo esforço assume também a conotação de imperativo ético e compromisso político. Trata-se de desviar da demonização e também da docilização (romantização, fetichização) da pobreza, e aprender a respeitá-la, experimentando mesmo o delicado e incontornável procedimento de desloca-la, em alguns casos, do lugar de problema social e testando interpela-la como portadora de saberes sobre a manutenção da vida, do laço social e das tecnologias da vila. Por fim, ressaltamos a importância de que no plano epistemológico, passemos, em um giro radical, a endereçar nossas lentes também à riqueza desmedida, conquistada de modo ilegítimo, e concentremos nossos esforços em transformá-la em problema social e sociológico. Que sejamos capazes de "envilecer a riqueza", como recomenda Tévoédrjè 
Descolonizar a imaginação talvez signifique, no plano das ciências sociais, liberar a imaginação sociológica para localizar novos alvos, para identificar outros inimigos da sociedade justa e atuar sobre eles com a mesma veemência com que, até aqui, se decretou guerra aos pobres. Descolonizar a imaginação nesse caso pode significar ajustar o foco sobre uma produtora de assimetria e injustiça social amplamente denunciada pelos intelectuais aqui citados: a riqueza desmedida.

\begin{abstract}
Notas
' Para um estudo mais aprofundado dessa questão, ver: Marques, P.M. Nou led, Nou La! Estamos feios, mas estamos aqui! Assombros haitianos à retórica colonial sobre pobreza. Tese. Programa de Pós-Graduação em Sociologia. Universidade Federal do Rio Grande do Sul, 2017.

2 No texto de Lobato, o elemento da raça aparece nitidamente como diferença que marca o início da ideia de modernização do rural brasileiro.

${ }^{3}$ Encontra-se disponível na internet cópia do manual distribuído em 1966, que está disponível em: https://bit.ly/3nFKTMD. Acceso em: 17 mar. 2021.

${ }^{4}$ Recomendamos, nesse sentido, a leitura de "Sob o olhar do outro: o experimento do racismo científico nas missões brasileiras de instruir e sanear populações pesqueiras" de Carolina Cyrino no livro Brasil, Haiti: Racismo, ciência, lutas históricas, dramas atuais, publicado pela Editora Fi em 2020.

${ }^{5}$ Disponível em: https://bit.ly/3gQkn1y. Acesso em: 18 de dez. 2020.

${ }^{6}$ Vale destacar que a crítica aqui apresentada não visa negar o acesso aos serviços públicos, pois trata-se de um Direito Constitucional. As populações rurais historicamente marginalizadas e expropriadas pelo empreendimento colonial necessitam de urgentes políticas de reparação
\end{abstract}

\section{Referências}

ANGLADE, G. Éloge de la Pauvreté. Montréal: ERCE Études et Recherches critiques d'espace, 1983. Edição completa, em francês, disponivel em: https://bit.ly/3uslXRh. Acesso em: 26 fev. 2021.

ANTUNES, A. L. O Manual dos Inquisidores. Lisboa: Dom Quixote, 1996.

ARENDT, H. Origens do totalitarismo. Tradução de Roberto Raposo. São Paulo: Companhia das Letras, 1989.

BEUVE-MERY A. «Georges Anglade, écrivain qué bécois d'origine haïtienne», Le Monde, 17 jan vier 2010. Disponível em: https://bit.ly/333plQu. Acesso em: 26 fev. 2021.

CAMPELLO, T. \& MELLO, J. O processo de formulação e os desafios do Plano Brasil Sem Miséria: por um país rico e com oportunidades para todos.Brasil. Ministério do Desenvolvimento Social e Combate à Fome. O Brasil Sem miséria. Brasília: MDS, 2014.
CASIMIR, J. La cultura oprimida. México: Nueva Imagen, 1980.

CATTANI, A. D. Ricos, Podres de Ricos. Porto Alegre: Tomo Editorial, 2018.

CESAIRE, Aimé. Discurso sobre o colonialismo. Prefácio de Mário de Andrade. Sá da Costa Editora: Lisboa, 1978.

CYRINO, C. Sob o olhar do outro: o experimento do racismo científico nas missões brasileiras de instruir e sanear populações pesqueiras.In: PADILHA, L \& MARQUES, P. M. (Orgs.) Brasil e Haiti: Racismo, Ciência, lutas históricas e dramas atuais [recurso eletrônico] - Porto Alegre, RS: Editora Fi, 2020.

DEPESTRE, René. Bonjour et adieu à la négritude. Paris: Robert Laffont, 1980. Versão em português disponível em: http://www.ufrgs. $\mathrm{br} / \mathrm{cdrom} /$ depestre/depestre.pdf, com acesso em 20 de dezembro de 2020; 
DEVELOPMENT WORKSHOP. MajidRahnema. Disponivel em <https://dwarchive.com/ majid-rahnema>. Acesso em: 27 fev. 2021.

ESCOBAR, A. La invencion del tercer mundo. El perro y la rana, 2007.

FAO/INCRA - ORGANIZAÇÃO DAS NAÇÕES UNIDAS PARA AGRICULTURA E ALIMENTAÇÃO (FAO) / INSTITUO NACIONAL DE COLONIZAÇÃO E REFORMA AGRÁRIA (INCRA). Diretrizes de política agrária e desenvolvimento sustentável para a pequena produção familiar. Brasília: FAO/ INCRA, 1994.

JUSTE, J. A. Internacional Comunitária: ONG's chamadas alternativas e Projeto de Livre Individualidade (crítica à parceria enquanto forma de solidariedade de espetáculo no desenvolvimento de comunidade no Haití); Tese de Doutorado apresentada ao Programa de Pós-Graduação em Serviço Social da Universidade Federal de Pernambuco, 2007.

LANDER, E. \& CASTRO-GÓMEZ, S. La colonialidad del saber: eurocentrismo y ciencias sociales: perspectivas latinoamericanas. Buenos Aires: ConsejoLatinoamericano de CienciasSociales-CLACSO, 2000.

LOBATO, M. Contos Completos. São Paulo: Biblioteca Azul, 2014.

MARQUES, P. M. "NOU LED, NOU LA!" "ESTAMOS FEIOS, MAS ESTAMOS AQUI!" Assombros haitianos à retórica colonial sobre pobreza. Tese de doutorado apresentada ao Programa de Pós-Graduação em Sociologia da Universidade Federal do Rio Grande do Sul, 2017.

MELLO, J.et al. Cadernos de Estudos Desenvolvimento Social em Debate. Brasília: Ministério do Desenvolvimento Social e Combate à Fome, 2015.

MIGNOLO, W. D. Desobediência epistêmica: a opção descolonial e o significado de identidade em política. Trad. Ângela Lopes Norte. Cadernos de Letras da UFF - Dossiê: Literatura, língua e identidade, n. 34, p. 287324, 2008;

RAHNEMA, M. The Richest of the Poor: An archeology of poverty.2001. Disponivel em:https://www.pudel.samerski.de/pdf/majid.pdf. Acessoem: 4 set. 2020.

RAHNEMA, M. Porvety. In: SACHS, W. The Development Dictionary: A Guide to Knowledge as Power, London \& New York: Zed Books, 2010.

SICILIA, J. Arte e Pensamento: MajidRahnema. La Jornada, 15 de mayo de 2015.

TÉVOÉDJRÈ, A. A pobreza, riqueza dos povos. São Paulo: Editora Cidade Nova. Co-edição Petropolis: Editora Vozes, 1981.

UQAM. Décès du professeur retraité Georges Anglade, 14 janvier 2010. Disponível em: http://www.nouvelles.uqam.ca/index. php?article=1421. Acesso em: 26 fev. 2021.

VIDJINGNINOU, F. \& MILLECAMPS, M. Bénin : Albert Tévoédjrè, figure intellectuelle et politique, est décédé. 06 novembre 2019. Disponivel em: https://bit.ly/3aOS93J. Acesso em: 27 fev. 2021.

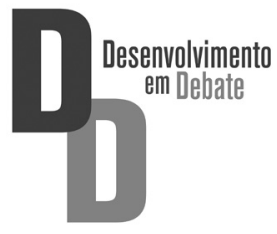

